\title{
Effect of intravaginal implants of melatonin on the onset of ovarian activity in adult and prepubertal ewes
}

\author{
R. Nowak and R. G. Rodway \\ Department of Animal Physiology and Nutrition \\ University of Leeds, Leeds LS2 9JT, U.K.
}

\begin{abstract}
Summary. Melatonin was administered intravaginally in Silastic tubing to adult and prepubertal ewes. In Exp. 1, ewe lambs (born early March) were given intravaginal melatonin implants at a mean age $( \pm$ s.e.m.) of $7.5 \pm 0.1$ weeks (Group $E, N=10$ ) or $19.4 \pm 0.2$ weeks (Group $L, N=10$ ). The third group (Group $C, N=10$ ) received empty implants. In Exp. 2 mature ewes were given implants on 13 May (Group E, N = 10 ) or $18 \mathrm{July}$ (Group L, N = 10) or received empty implants (Group C, N=10) on one of these two dates. Blood samples were taken twice weekly for progesterone assay. In Exp. 1 the mean age ( \pm s.e.m.) at puberty (progesterone $>2 \mathrm{nmol} / 1$ for two consecutive samples) was $35.4 \pm 0.8$ weeks. Puberty was advanced by 5.2 weeks in Group L lambs, occurring at a mean age of $30.2 \pm 0.7$ weeks $(P<0.001)$. In Group E lambs the timing of puberty was unaltered, occurring at a mean age of $34.8 \pm 0.6$ weeks. Mature ewes in Group L (Exp. 2) showed increased incidence of ovarian activity $(9 / 10$ ewes cycling by 26 September) compared with the control ewes $(1 / 10)(P<0.001)$, but there was no effect in Group $E$ ewes $(3 / 10)$. The results demonstrate that continuous melatonin administration to adult and prepubertal ewes can mimic the effect of short days in terms of the reproductive response, and that the present and previous exposure to melatonin is critical in determining the response.
\end{abstract}

\section{Introduction}

The pineal indoleamine, melatonin, has been proposed to be the hormone that mediates the photoperiodic regulation of seasonal breeding. It has been demonstrated that melatonin drives the reproductive response of the ewe to inductive photoperiods (Bittman, Dempsey \& Karsch, 1983). The rhythmic administration of melatonin, by feeding or injection, can substitute for darkness to induce the onset of the breeding season in the adult ewe (Kennaway, Gilmore \& Seamark, 1982a; Nett \& Niswender, 1982; Arendt, Symons, Laud \& Pryde, 1983). In these experiments melatonin was administered in the mid-afternoon to seasonally anoestrous ewes kept on inhibitory lighting regimens in an attempt to mimic the physiological plasma melatonin profiles that occur in ewes maintained on stimulatory lighting regimens. Whether the characteristic short-day profile of melatonin is essential for the initiation of the short-day reproductive response in the ewe is unknown. However, the continuous administration of melatonin via subcutaneous implants will advance the onset of the rut in the stag (Lincoln, Fraser \& Fletcher, 1984) and ram (Lincoln \& Ebling, 1985), and in the adult ewe will cause changes in plasma prolactin concentrations similar to those seen following exposure to short days (Kennaway, Dunstan, Gilmore \& Seamark, 1983). In the present study the effect of continuous melatonin administration via intravaginal implants was investigated to determine whether the characteristic short-day plasma melatonin profile is essential for the short-day reproductive response in the adult ewe. 
As the timing of puberty is altered in ewe lambs born out of their normal season of birth, seasonal factors must influence the onset of ovarian activity in these animals. As in the adult ewe, photoperiod has been found to be the major seasonal cue in the ewe lamb (Foster, 1981). Premature exposure of ewe lambs to a short day can delay or advance the onset of puberty (Foster, 1983), the response being dependent on the age at first exposure, with both the prevailing and previous photoperiod influencing the timing, quantity and quality of the first ovarian cycles. Although lambs are known to show rhythmic pineal function from as young as 6 weeks of age (Rodway, Swift, Nowak, Smith \& Padwick, 1985), the role of the pineal gland in the control of puberty is unclear. However, the continuous administration of melatonin from 3-4 weeks of age delays the onset of puberty in the ewe lamb (Kennaway \& Gilmore, 1984).

A further objective of the present investigation was to determine whether the response of the ewe lamb to continuous melatonin, as to short-day treatment, was age dependent and whether the short day reproductive response in the lamb was likely to be mediated via melatonin.

\section{Materials and Methods}

Seasonally anoestrous Mule ewes (4-5 years old, $N=30$ ) and 30 prepubertal Mule $\times$ Suffolk ewe lambs (born 2-24 March, 1983) were used. The animals were kept outside at the Leeds University Field Station (latitude $53^{\circ} 52^{\prime} \mathrm{N}$ ).

Melatonin implants were prepared from Silastic medical grade tubing (o.d. $0.24 \mathrm{~cm}$, i.d. $0 \cdot 16$ $\mathrm{cm}$; Dow Corning Corporation, Midland, MI, U.S.A.). Tubing lengths of $30 \mathrm{~cm}$ (ewes), $20 \mathrm{~cm}$ (lambs > 19 weeks) and $15 \mathrm{~cm}$ (lambs $<19$ weeks) were packed with crystalline melatonin (Sigma, St Louis, MO, U.S.A.; $8.5 \mathrm{mg} / \mathrm{cm}$ tubing). Implants were held in position in the vagina by polyurethane sponges (fabricated in this laboratory).

Experiment 1. Ten lambs (Group E) were given intravaginal implants of melatonin at a mean age ( \pm s.e.m.) of $7.5 \pm 0.1$ weeks on 13 May 1983 (Day 1 ; prevailing photoperiod $16 \mathrm{~h} \mathrm{light:8 \textrm {h }}$ dark). On 18 July 1983 (Day 67; prevailing photoperiod 16L:8D) the original implants were replaced and 10 other lambs (Group L) were given implants at a mean age of $19.4 \pm 0.2$ weeks. The remaining 10 lambs (Group C) received empty implants on one of these dates. All implants were removed on 9 December 1983 (Day 211). The lambs were weighed on Days 56, 71, 106 and 211.

Experiment 2. Thirty ewes received intravaginal implants of melatonin on 13 May 1983 (Day 1; $\mathrm{N}=10 ;$ Group E) or $18 \mathrm{July} 1983$ (Day $67 ; \mathrm{N}=10$; Group L) or received empty implants on one of these days $(\mathbf{N}=10$; Group $C$ ). Group E ewes had their original implants replaced on 18 July (Day 67). The ewes were shorn on 10 July (Day 29). All animals were weaned on 2 September (Day 113). For flock management purposes the implants were removed and the experiment terminated on 25 September 1983 (Day 137). From 10 October the ewes were run with the rams. Lambing dates for 1984 were recorded.

In both experiments, twice weekly from the placement to the removal of the implants, blood was collected by jugular venepuncture and the implants were checked and replaced if necessary. The blood was heparinized, centrifuged and stored at $-20^{\circ} \mathrm{C}$ until required for assay.

Hormone assay. Plasma samples were analysed for progesterone by radioimmunoassay (Senior, Cawood, Oakey, McKiddie \& Siddle, 1978). The minimal detectable dose of the assay with $95 \%$ confidence was $1 \cdot 1 \mathrm{nmol} / 1$. Standard plasma with progesterone concentrations of $20 \cdot 1,9 \cdot 0$ and $5 \cdot 5$ nmol/l generated interassay coefficients of variation of $14.4 \%, 17.7 \%$ and $10.9 \%$, respectively. The intra-assay coefficients of variation at 2.1 and $12.5 \mathrm{nmol} / 1$ were $16.1 \%$ and $9.4 \%$, respectively.

Statistical analysis. Ewe and lamb treatment responses and lamb group weight differences were assessed by analysis of variance. The age at puberty was tested for significant treatment effect and weight effect by analysis of co-variance. All means are expressed as \pm s.e.m. 


\section{Results}

Implant loss was infrequent, occurring at the rate of one loss every 47 and 52 sheep weeks for the lambs and ewes respectively. However, 2 lambs (one from Group E and one from Group L) which repeatedly lost their implants were removed from the experiment.

Progesterone values of $>2 \mathrm{nmol} / 1$ for two consecutive samples were taken to indicate the onset of ovarian activity. In Exp. 1, lambs that had not started cycling by the end of the experiment ( 2 in Group C, 2 in Group E but none in Group L) were said to have commenced ovarian activity on the last day of the experiment ( 9 December, Day 211) for statistical purposes.

\section{Experiment 1: melatonin implants and puberty in ewe lambs}

Text-figure 1 clearly shows that puberty was advanced in Group L lambs compared with that of lambs in Groups $\mathrm{E}$ and $\mathrm{C}$. In Group $\mathrm{C}$ lambs cyclic activity, i.e. puberty, began at a mean age of $35.4 \pm 0.8$ weeks on Day $187 \pm 5$ (15 November). Puberty was advanced by 5.2 weeks in Group $L$ lambs occurring at a mean age of $30.2 \pm 0.7$ weeks on Day $143 \pm 5$ ( 2 October), 10.8 weeks after implantation. In Group $E$ the timing of puberty was unaltered, occurring at a mean age of $34.8 \pm$ 0.6 weeks on Day $191 \pm 4$ (19 November) by which time the lambs had had implants for 27.3 weeks. The differences between the lambs in Group $L$ and those in Groups $E$ and $C$ in age at, and time of, puberty are significant $(P<0.001, P<0.001$ respectively; analysis of variance and Duncan's multiple range test). The lamb in Group $E$ that appeared to reach puberty several months in advance of the other lambs on the same treatment in fact had elevated plasma progesterone levels for two consecutive samples on Days 123 and $127(2.4$ and $2.2 \mathrm{nmol} / 1$ respectively) but progesterone was then undetectable until Day 194 (see Text-fig. 2). For statistical purposes this one aberrant animal was said to have started cycling on Day 194.

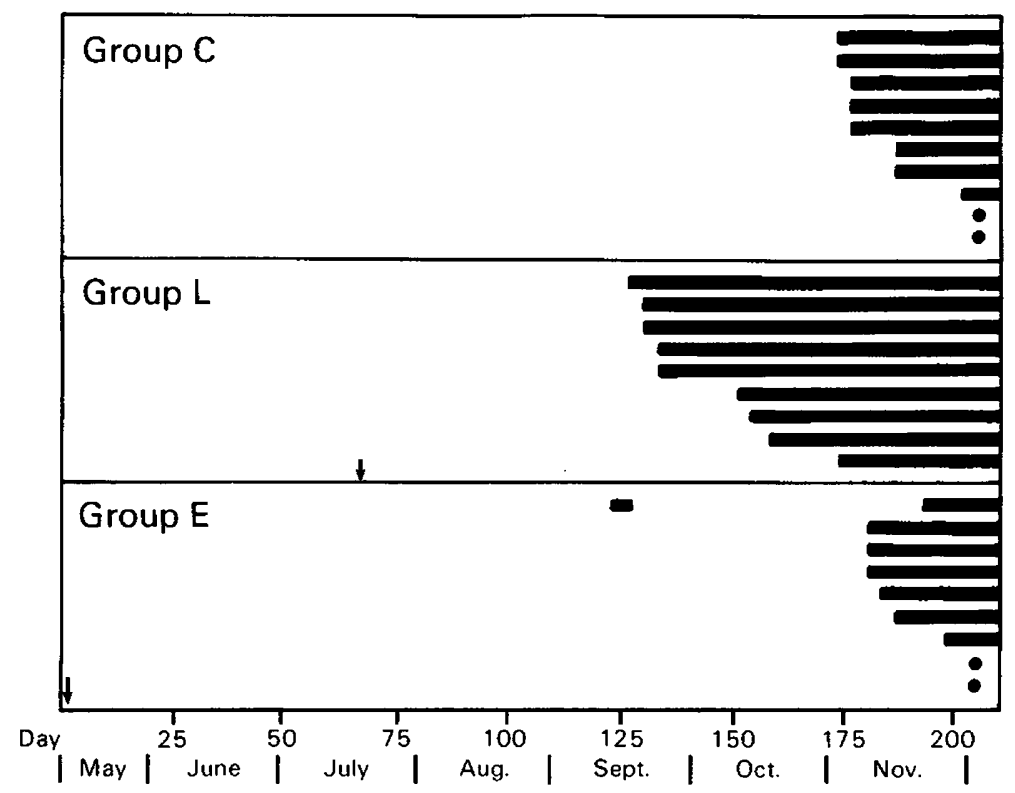

Text-fig. 1. Occurrence of ovarian cycles (solid bars) in Suffolk $\times$ Mule ewe lambs in Group C (empty implants), Group $L$ (melatonin implants from a mean age of $19.4 \pm 0.2$ weeks) and Group $E$ (melatonin implants from a mean age of $7.5 \pm 0.1$ weeks). Arrows indicate time of implant insertion. Day $1=13$ May. Reproductive status was monitored by measurement of plasma progesterone concentrations: values of $>2 \mathrm{nmol} / 1$ for 2 consecutive samples were taken to indicate the onset of ovarian activity. Plasma progesterone had not exceeded $2 \mathrm{nmol} / \mathrm{l}$ for two consecutive samples by Day 211 . 

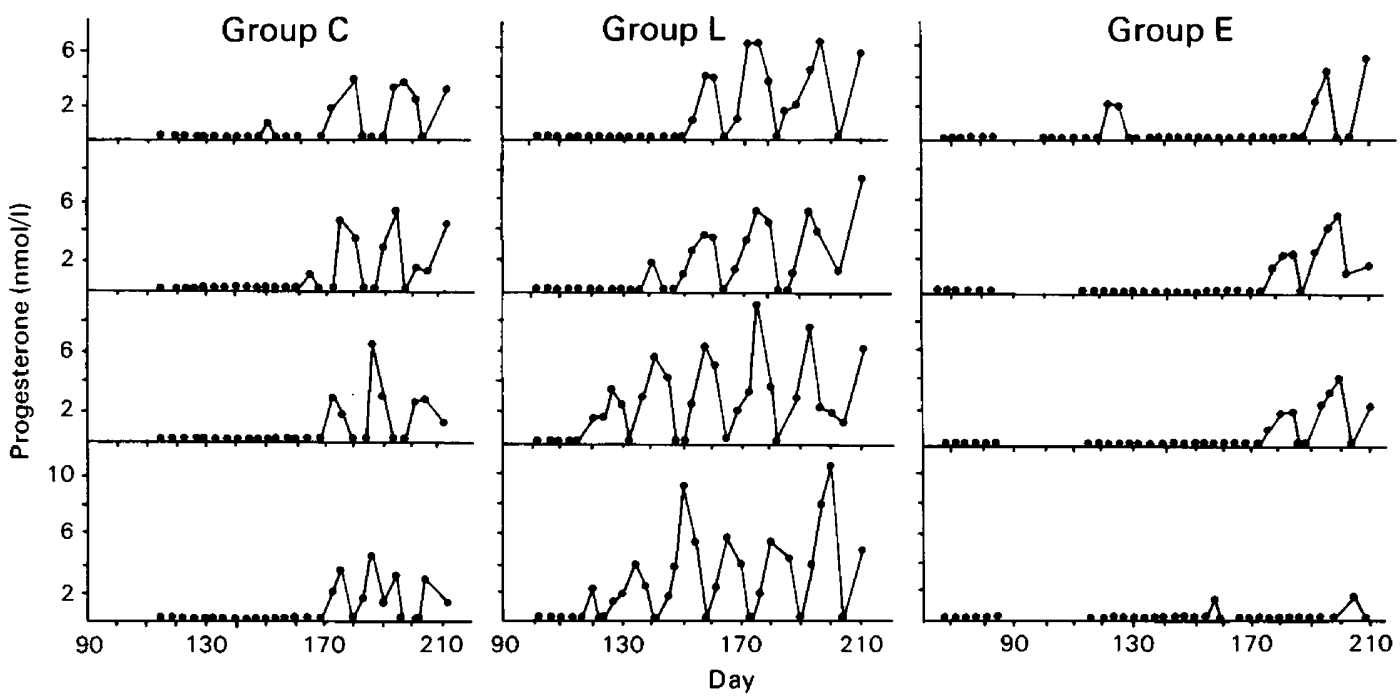

Text-fig. 2. Progesterone profiles of representative lambs from Groups C, L and E. Day $1=13$ May.

Text-figure 2 shows the progesterone profiles of representative lambs from each group. Progesterone concentrations were undetectable in Group E lambs (Text-fig. 2c) at 11 weeks after implantation (Day 77) but had started to increase by 11 weeks after implantation (Day 147) in Group L lambs (Text-fig. 2b). The progesterone profiles of Group L lambs showed that cyclicity was sustained and that cycles were normal in terms of duration of increased progesterone concentrations and progesterone peak height.

\section{Effect of weight on puberty}

On no occasions were the mean body weights of lambs in Groups $\mathrm{E}$ and $\mathrm{L}$ significantly different from those of the control group (Group C). On Days 56, 71 and 106 lambs in Group E were significantly lighter (39.1 $\pm 1 \cdot 3,39.6 \pm 1.3$ and $40.4 \pm 1.0 \mathrm{~kg}$ respectively) than those in Group $\mathrm{L}$ $(44.3 \pm 1.6,44.7 \pm 1.3$ and $44.7 \pm 1.4 \mathrm{~kg}$, respectively $)(P<0.05$, analysis of variance and Duncan's multiple range test). However, by Day 211 the difference was no longer significant. All lambs were $>35 \mathrm{~kg}$ by Day 56 . To examine the effects of treatment whilst taking into account the observed differences in weight, analyses of variance with one covariant (weight) were carried out. Weight on Day 56 had a significant effect on the age at puberty $(P<0 \cdot 05$, d.f. $=1$, mean square $=$ 24.6) giving adjusted means of 35.4 weeks, 30.9 weeks and 34.3 weeks for lambs in Groups $C, L$ and $\mathrm{E}$, respectively. However, even after removal of the effect of weight the differences found in age at puberty between lambs in Group $L$ and those in Groups $E$ and $C$ remained significant $(P<0.001$, d.f. $=2$, mean square $=44 \cdot 3$ ). Weight on Days 72,106 or 211 had no effect on age at puberty.

\section{Experiment 2: melatonin implants and ovarian activity in adult ewes}

The incidence of ovarian activity was significantly increased in Group L ewes (Text-fig. 3); 9 out of 10 had started to cycle by 26 September (mean onset, Day $120 \pm 4$; 9 September) compared with 1 out of 10 of the control ewes $(P<0.001$, Fisher Test). Only 3 out of the 10 ewes in Group E showed ovarian activity. The ewe in Group $E$ that appeared to enter the breeding season on Day 95 in fact had elevated progesterone concentrations for 3 consecutive samples on Days 95,99 and 102 $(2.0,3.5$ and $3.6 \mathrm{nmol} / 1$ respectively) but values were then undetectable for the remainder of the 


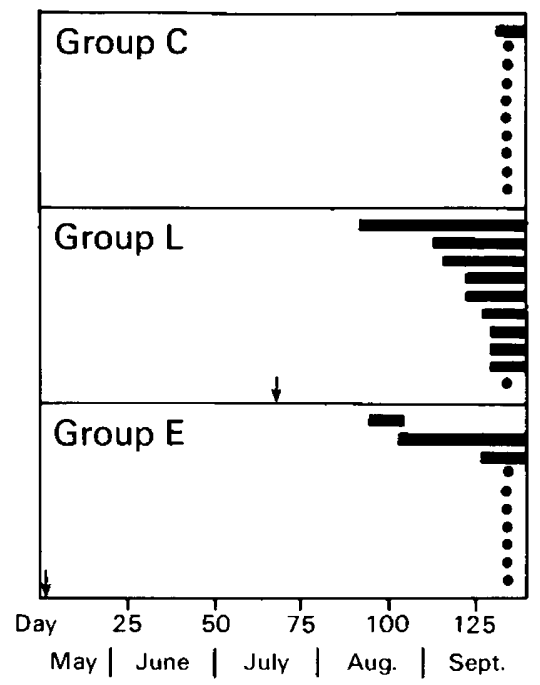

Text-fig. 3. Occurrence of ovarian cycles (solid bar) in Mule ewes in Group C (empty implants), Group L (melatonin implants from $18 \mathrm{July} 1983$ (Day 67)), and Group E (melatonin implants from 13 May (Day 1)). Arrows indicate time of implant insertion. Reproductive status was monitored by measurement of plasma progesterone concentrations: values $>2 \mathrm{nmol} / \mathrm{l}$ for two consecutive samples were taken to indicate the onset of ovarian activity. Plasma progesterone had not exceeded $2 \mathrm{nmol} / \mathrm{l}$ for two consecutive samples by Day 137 .

experiment. Although the fertility of the lambs and ewes during the induced cycles was not tested, there was no significant difference in the lambing dates between the 3 groups of ewes, demonstrating that subsequent cycles were fertile.

\section{Discussion}

Melatonin administration from mid-July advanced the onset of cyclic ovarian activity in ewe lambs and adult ewes. Intravaginal implants provide a more convenient method of melatonin administration than the rhythmic administration by injection, infusion or feeding, and are equally effective in manipulating ovarian activity. Although subcutaneous melatonin implants have been shown to suppress plasma prolactin concentrations in ewes (Kennaway et al., 1983) and rams (Lincoln \& Ebling, 1985), advance the onset of the rut in the ram (Lincoln \& Ebling, 1985) and the stag (Lincoln et al., 1984) and delay the onset of puberty in the ewe lamb (Kennaway \& Gilmore, 1984), this is the first report of melatonin implants being able to mimic the effect of short days, in terms of the reproductive response, in the adult ewe and ewe lamb. As the release of melatonin from Silastic is constant (Kennaway et al., 1983), this suggests that the characteristic short-day plasma melatonin profile is not essential for bringing about the associated reproductive changes. Melatonin implants from mid-May failed to advance the onset of ovarian activity in adult or prepubertal ewes. The response to melatonin administration from mid-July was impaired by the earlier exposure to the hormone, indicating that both the present and previous exposure to melatonin is critical in determining the response.

Other factors, besides photoperiod, have an effect on the time of the first ovulation in the lamb. A uniform 'critical' body weight for the initiation of puberty is not thought to exist in the ewe lamb (Foster \& Ryan, 1979). In the present study first ovulation occurred over a wide range of bodyweights $(36-52 \mathrm{~kg}$ ) with no ranking of first ovulation with weight. However, it has been suggested that there is a threshold bodyweight below which puberty cannot be initiated (Keane, 
1974), and the significant effect of weight on Day 56 on the age at puberty may reflect the effect this weight has on the time taken to attain the threshold bodyweight.

Although early studies concluded that photoperiod played no major role in the onset of ovarian activity in the ewe lamb (Radford, 1961; Smith, 1967; Ducker, Bowman \& Temple, 1973), Foster $(1981,1983)$ has demonstrated that photoperiod profoundly influences both the initiation and maintenance of reproduction in the ewe lamb. Premature exposure of ewe lambs to short photoperiods advanced or delayed the onset of ovarian activity depending on the age at onset of treatment, and Foster (1983) concluded that prior exposure to long days was required for the initiation of ovulation under subsequent short days. In the present study melatonin implants from the age of 7.5 weeks had no effect on the onset of ovarian activity, whereas implants from 19.5 weeks of age advanced it. Kennaway \& Gilmore (1984) found that subcutaneous implants from 3-4 weeks of age had a delaying effect on the onset of ovarian activity. These findings, when taken together, indicate that there is an age-dependent response to melatonin and suggest that, as in the adult ewe, melatonin mediates the photoperiodic response in the ewe lamb.

The mechanism governing the age-dependent response to melatonin is unknown. There are at least three possible explanations, not necessarily mutually exclusive. Firstly, the early exposure of the lambs to melatonin, whilst below some threshold bodyweight and so incapable of responding, may have rendered them refractory to the hormone by the time they eventually exceeded the threshold weight. Secondly, during early development the lamb may establish the prevailing levels of melatonin as indicative of a long, inhibitory photoperiod. It may be the lack of contrast between low (summer) melatonin levels and high (autumn) melatonin levels that is preventing the early implanted lambs from responding to the high circulatory levels in July. As there is no feedback of melatonin upon its own secretion, the eventual onset of puberty in the early treated lambs may have been induced by an increase in the endogenous melatonin secretion in response to the shortening daylength, superimposed upon the basal melatonin levels produced by the implants (Kennaway $e t$ al., 1982b; Kennaway \& Gilmore, 1984). Thirdly, melatonin could also act, not by suppressing the expression of sexual competence, but by retarding the developmental processes necessary for the attainment of sexual maturity.

In the adult ewe there is also a differential effect of melatonin exposure depending on the time of onset of treatment; treatment from mid-May has no effect, whereas treatment from mid-July advances the onset of the breeding season. As implants given in mid-May were replaced by fresh implants in mid-July, exhaustion of the implants does not explain the lack of effect of early treatment. However, one explanation could be that by mid-May the ewe has not experienced a sufficient number of long days for the refractoriness to short-days (and hence high melatonin) to be removed. This suggestion is not compelling, because although melatonin administration from early spring has been reported to be ineffective in advancing the breeding season (Nett \& Niswender, 1982), spring melatonin treatment is effective if it is preceded by only 4 weeks of artificial long days (16L : 8D) (Kennaway et al., 1982a). Moreover, melatonin implants from mid-May in the adult stag advance the onset of the rut (Lincoln et al., 1984). This combined information suggests that it is unlikely that refractoriness to melatonin treatment should persist until mid-May, when the prevailing photoperiod was $16 \mathrm{~L}: 8 \mathrm{D}$. An alternative explanation is that initially the Group $\mathrm{E}$ ewes were in lactational anoestrus and therefore incapable of responding to the melatonin, and that by the end of lactational anoestrus the prolonged exposure to melatonin had rendered them refractory. Lactating red deer have also been found to be unresponsive to melatonin treatment (Nowak, Elmhirst \& Rodway, 1985). Further experiments are necessary to distinguish between the effects of photoperiod and lactation on the response of the ewe to melatonin treatment.

Two explanations for the reproductive response to melatonin must be considered. Continuous melatonin administration may act by preventing the animal from perceiving the prevailing daylength, and so, without the restraining influences of the photoperiod, permit expression of an inherent cycle of reproductive changes. An alternative explanation is that continuous exposure to melatonin is perceived by the animal as a short day and so initiates the appropriate reproductive 
changes. If the former explanation is correct one would expect the early implanted ewes to enter the breeding season before or at the same time as, but not later than, the late implanted ewes. In addition, the findings discussed here have indicated the ability of continuous melatonin to mimic the age-dependent effects of short-day treatment in the prepubertal lamb. We therefore conclude that continuous melatonin treatment is perceived by the ewe as a short, stimulatory photoperiod.

We thank Dr G. S. Pope for the progesterone antiserum and Professor S. R. Stitch for making available the facilities of the Division of Steroid Endocrinology.

\section{References}

Arendt, J., Symons, A.M., Laud, C.A. \& Pryde, S.J. (1983) Melatonin can induce the early onset of the breeding season in ewes. J. Endocr. 97, 395-400.

Bittman, E.L., Dempsey, R.J. \& Karsch, F.J. (1983) Pineal melatonin drives the reproductive response to daylength in the ewe. Endocrinology 113, 2275-2283.

Ducker, M.J., Bowman, J.C. \& Temple, A. (1973) The effect of constant photoperiod on the expression of oestrus in the ewe. J. Reprod. Fert., Suppl. 19, 143150.

Foster, D.L. (1981) Mechanism for delay of first ovulation in lambs born in the wrong season (fall). Biol. Reprod. 25, 85-92.

Foster, D.L. (1983) Photoperiod and sexual maturation of the female lamb: early exposure to short days perturbs estradiol feedback inhibition of luteinizing hormone secretion and produces abnormal ovarian cycles. Endocrinology 112, 11-17.

Foster, D.L. \& Ryan, K.D. (1979) Endocrine mechanisms governing the transition into adulthood: A marked decrease in inhibitory feedback action of estradiol on tonic secretion of luteinizing hormone in the lamb during puberty. Endocrinology 105, 896-904.

Keane, M.G. (1974) Effect of bodyweight on attainment of puberty and reproductive performance in Suffolk ewe lambs. Ir. J. agric. Res. 13, 263-274.

Kennaway, D.J. \& Gilmore, T.A. (1984) Effects of melatonin implants in ewe lambs. J. Reprod. Fert. 70, 39-45.

Kennaway, D.J., Gilmore, T.A. \& Seamark, R.F. (1982a) Effect of melatonin feeding on serum prolactin and gonadotropin levels and the onset of seasonal estrous cyclicity in sheep. Endocrinology 110, 1766-1772.

Kennaway, D.J., Gilmore, T.A. \& Seamark, R.F. (1982b) Effects of melatonin implants on the circadian rhythm of plasma melatonin and prolactin in sheep. Endocrinology 110, 2186-2188.
Kennaway, D.J., Dunstan, E.A., Gilmore, T.A. \& Seamark, R.F. (1983) Effect of shortening daylength and melatonin treatment on plasma prolactin and melatonin levels in pinealectomized and sham-operated ewes. Anim. Reprod. Sci. 5, 287-294.

Lincoln, G.A. \& Ebling, F.J.P. (1985) Effect of constantrelease implants of melatonin on seasonal cycles in reproduction, prolactin secretion and moulting in rams. J. Reprod. Fert. 73, 241-253.

Lincoln, G.A., Fraser, H.M. \& Fletcher, T.J. (1984) Induction of early rutting in male red deer (Cervus elaphus) by melatonin and its dependence on LHRH. J. Reprod. Fert. 72, 339-343.

Nett, T.M. \& Niswender, G.D. (1982) Influence of exogenous melatonin on seasonality of reproduction in sheep. Theriogenology 17, 645-653.

Nowak, R., Elmhirst, R.N. \& Rodway, R.G. (1985) A note on the effect of melatonin feeding on the initiation of ovarian activity and on plasma prolactin levels in lactating and non-lactating Red deer hinds. Anim. Prod. 40, in press.

Radford, H.M. (1961) Photoperiodism and sexual activity in Merino ewes. Aust. J. agric. Res. 12, 139-146.

Rodway, R.G., Swift, A.D., Nowak, R., Smith, J.A. \& Padwick, J.A. (1985) Plasma concentrations of melatonin and the onset of puberty in the female lamb. Anim. Reprod. Sci., in press.

Senior, B.F., Cawood, M.L., Oakey, R.E., McKiddie, J.M. \& Siddle, D.R. (1978) A comparison of the effects of clomiphene and tamoxifen treatment on the concentrations of oestradiol and progesterone in the peripheral plasma of infertile women. Clin. Endocr. 8, 381-389.

Smith, I.D. (1967) The effect of constant long daily photoperiod upon the onset of puberty in ewes. $J$. agric. Sci., Camb. 69, 43-45. 